\title{
DO DISCURSO DO ÓDIO CONTRA MINORIAS SEXUAIS: DA DIALÉTICA ENTRE O PRINCÍPIO DA DIGNIDADE DA PESSOA HUMANA E A LIBERDADE DE EXPRESSÃO
}

\section{HATE SPEECH AGAINST SEXUAL MINORITIES: DIALECTIC BETWEEN THE PRINCIPLE OF HUMAN DIGNITY AND FREEDOM OF EXPRESSION}

\section{RESUMO}

Sabe-se que minorias e grupos vulneráveis constituem, frequentemente, alvo de expressões discriminatórias no Brasil. No que tange às minorias sexuais, observam-se como autores de manifestações contrárias os fanáticos religiosos, moralistas extremados e outros motivados por razões pessoais diversas, mas que dificilmente constituem justificativas plausíveis para a conduta. Pelo contrário, via de regra, acabam por imprimir às suas manifestações um discurso do ódio, o que incita não só o preconceito, a repugnância, mas até mesmo a violência contra tais grupos. Uma vez que a Constituição Federal de 1988 consagrou um sistema de direitos fundamentais, permeiam nosso ordenamento jurídico os princípios da dignidade da pessoa humana e da liberdade de expressão. Pode-se afirmar, inclusive, que este último só se justifica quando atendidos os limites daquele, que constitui um dos fundamentos da República Federativa do Brasil. Todavia, só é possível se analisar se a prática discursiva não acaba por se enquadrar no discurso do ódio - o que ultrapassa os limites da liberdade de manifestação do pensamento e viola a dignidade humana -, mediante a análise caso a caso, de acordo com a observância do princípio da proporcionalidade.

Palavras-chave: Discurso do ódio, Dignidade da pessoa humana, Liberdade de expressão, Proporcionalidade

\footnotetext{
${ }^{1}$ Mestrado em andamento em Ciências Jurídicas. Centro Universitário Cesumar, UNICESUMAR. Paraná - PR, Brasil. Email: indexlaw.ojs@ hotmail.com

${ }^{2}$ Graduação em Direito pelo Centro Universitário Cesumar, UNICESUMAR. Paraná - PR, Brasil.

E-mail: Indexlaw.ojs@ hotmail.com
} 


\begin{abstract}
It is known that minorities and vulnerable groups are often the target of discriminatory expressions in Brazil. About sexual minorities, as authors of counter demonstrations there ligious fanatics, moralists extreme and other motivated by personal reasons, but that hardly constitute plausible justifications for the conduct. On the contrary, as a rule, they printat their demonstrations a hate speech, urging not only prejudice, repugnance, but even violence against such groups. Sincethe 1988 Federal Constitutionen shrines a system of fundamental rights, permeate our legal system the principles of human dignity and freedom of expression. It can be affirmed, inclusive, that the latter is justifie donly when it metthe limit softhat which constitutes one of the foundations of the Federative Republic of Brazil. However, it is only possible to analyze if the discursive practice doesn't stop fall in hate speech-which exceeds the limits off reedom of expression of thought and violates the human dignity, by examining a case-by-case basis, in accordance with the principle of proportionality.
\end{abstract}

Keywords/Palabras-claves/Mots-clés: Hate speech, Dignity of the human person, Freedom of expression, Proportionality

\title{
1 INTRODUÇÃO
}

Após o longo período de ditadura militar no Brasil, iniciado no ano de 1964, que limitou, e até mesmo expurgou, as liberdades e as garantias individuais e sociais até então conquistadas, aos cinco dias do mês de outubro do ano de mil novecentos e oitenta e oito foi promulgada a atual Constituição Federal.

No intuito de redemocratizar a nação, bem como de restaurar e de tutelar os direitos mais importantes da pessoa humana, a "Constituição Cidadã" consagrou, em seu bojo, um sistema de direitos fundamentais.

Assim, estabeleceu uma série de objetivos e princípios norteadores para a consolidação da sociedade livre, justa, inclusiva e democrática tão almejada pelo povo.

Nesse sentido, no inciso III de seu artigo $1^{\circ}$, dispôs sobre o princípio da dignidade da 
pessoa humana, considerando-o fundamento da República. Mais do que isso, a nova ordem constitucional lhe atribuiu o valor unificador dos direitos fundamentais, garantindo à pessoa seu pleno desenvolvimento físico, psíquico e emocional, isto é, conferindo-lhe proteção integral.

Pelo novo sistema constitucional, também se considera a liberdade como princípio fundamental do Estado Democrático de Direito.

Tal princípio confere ampla proteção às suas variadas vertentes, dentre elas, a liberdade de expressão, direito fundamental disposto no inciso IV do artigo $5^{\circ}$. da Constituição Federal. Mediante este, garante-se ao sujeito a livre manifestação do pensamento e da exposição das mais diversas opiniões e posições ideológicas.

Ademais, em razão da censura exacerbada do regime ditatorial, a liberdade de expressão representa uma conquista fundamental e de ímpar relevância na implementação e manutenção do bem-estar social.

Por meio dela, além de se proporcionar o diálogo entre pensamentos contrários, admitem-se críticas ao próprio Estado, o que corrobora com o exercício da democracia.

Observa-se, no entanto, que a liberdade de expressão é muitas vezes utilizada como meio de se exteriorizarem pensamentos discriminatórios, imbuídos do ânimo de diminuir, insultar e desqualificar determinadas pessoas e grupos simplesmente em virtude de suas características peculiares. Nesses casos, fala-se em discurso do ódio.

No caso das minorias sexuais, a referida conduta acaba por estimular, ainda que veladamente, a prática de ações discriminatórias e preconceituosas. Na maioria das vezes,

viola-se não somente a dignidade do indivíduo diretamente vitimado pela ofensa, mas a deste grupo social como um todo.

Hodiernamente, observa-se a expansão de grupos contrários ao reconhecimento dos direitos civis e da dignidade dos sujeitos homoafetivos e transgêneros.

Segmentos conservadores da sociedade se utilizam de argumentos fundados em discursos religiosos fanáticos para atribuir às minorias sexuais o caráter de degenerados e, assim, proferem uma prática discursiva carregada de valores negativos e com o fim de 
subjugar, inferiorizar e desqualificar a referida comunidade.

Visto que sequer a dignidade da pessoa humana corresponde a um direito absoluto, a liberdade de expressão também não pode ser considerada como tal. Faz-se, necessário balizar seus limites, em especial, quando o referido direito fundamental é utilizado com a pretensão de legitimar um discurso do ódio que incita a violência contra as pessoas transexuais, travestis, gays, bissexuais e mulheres lesbianas.

A partir dessa reflexão, por meio do método teórico, pretende-se analisar o princípio da dignidade da pessoa humana tanto como fundamento quanto como limite ao exercício da liberdade de expressão. Apontando-se o princípio da proporcionalidade como meio de solução ao caso concreto em que se apura determinado conflito gerado pela colisão entre tais direitos fundamentais que envolvem as minorias sexuais.

\section{DA LIBERDADE DE EXPRESSÃO E DO DISCURSO DO ÓDIO}

A liberdade de expressão é direito fundamental consagrado pelo ordenamento jurídico brasileiro, que a disciplina nos incisos IV e IX do art. $5^{\circ}$ da Constituição Federal de 1988, in verbis:

\footnotetext{
“(...) IV - É livre a manifestação do pensamento, sendo vedado o anonimato.

(...) "IX - É livre a expressão da atividade intelectual, artística, científica e de comunicação, independentemente de censura ou licença."
}

Como o próprio nome sugere, corresponde a desdobramento do direito fundamental à liberdade e se refere ao direito conferido a todo indivíduo de exteriorizar livremente suas convicções.

Acerca do tema, Marco Antônio de Mello assevera:

“(...) o específico direito fundamental da liberdade de expressão exerce um papel de extrema relevância em suas mais variadas facetas: direito de opinião, direito de imprensa, direito à informação e direito à proibição à censura. A liberdade de expressão decorre da liberdade de pensamento, sendo a garantia da livre manifestação deste por meio de palavras, escritos, imagens ou qualquer outra forma de exteriorização".(MELLO, 2009, p.246) 
Observa-se que a liberdade de expressão significa um marco na história da conquista dos direitos individuais, pois confere ao sujeito o direito ao exercício da livre manifestação do pensamento e a exposição das mais variadas opiniões e posições ideológicas, sendo, inclusive, um instrumento de controle da atividade governamental e do exercício do poder. (MELLO, 2009, p. 240)

Apesar da extrema relevância da referida liberdade para a manutenção do Estado Democrático de Direito, deve-se ponderar acerca de sua aplicação irrestrita, ainda que tutelada pelo ordenamento constitucional.

Segundo Samanta Ribeiro Meyer-Pflug, tal princípio sofre algumas restrições, pois "há de se respeitar outros valores albergados pela ordem constitucional vigente, alguns deles constam no próprio Texto Constitucional com repercussão na legislação infraconstitucional" (MEYER-PFLUG , 2009, p. 83).

Denota-se, portanto, que apesar da relevância do referido direito - compreendido como fundamental na manutenção de um Estado pluralista como o nosso, visto ensejar a possibilidade de diálogo entre diversas opiniões e posicionamentos ideológicos - não pode ser concebido como um direito absoluto.

Assim, quando da colisão entre o exercício da liberdade de expressão e de outros direitos fundamentais, deve-se ponderar qual se fará sobressalente, sob pena de se incorrer em injustiça.

Destaca-se, ainda, que o embasamento teórico para a liberdade de expressão ser considerada um direito fundamental é, justamente, o princípio da dignidade da pessoa humana.

Disciplinado no inciso III, do artigo $1^{\circ}$ da Constituição Federal, o princípio da dignidade da pessoa humana é estabelecido como fundamento da República Federativa do Brasil e pode ser compreendido como o atributo moral do indivíduo, ou seja, aquilo que o qualifica enquanto ser humano (SIQUEIRA JR, 2009, p. 273). Confira-se:

“Art. $1^{\circ}$ A República Federativa do Brasil, formada pela união indissolúvel dos Estados e Municípios e do Distrito Federal, constitui-se em Estado Democrático de Direito e tem como fundamentos: 


$$
\text { (...) - a dignidade da pessoa humana." }
$$

Trata-se, pois, de "elemento inato aos homens, implica em liberdade, igualdade e justiça, constituindo o fundamento da organização social contemporânea”.(SILVA, 2009)

O principio da dignidade da pessoa humana, segundo Ingo Wolfgang Sarlet, é a "qualidade intrínseca e distintiva de cada ser humano que o faz merecedor do mesmo respeito e consideração por parte do Estado e da comunidade" (SARLET, 2001, p. 70)

Deste modo, afirmar a dignidade da pessoa humana como um princípio norteador do ordenamento jurídico, para o autor supracitado, implica em garantir à pessoa a tutela "contra todo e qualquer ato de cunho degradante e desumano (...) além de propiciar e promover sua participação ativa e co-responsável nos destinos da própria existência e da vida em comunhão com os demais seres humanos". (SARLET, 2001, p. 70)

Acerca do referido princípio, Alexandre de Moraes assevera que este apresenta-se em uma dupla concepção, pois “(...) prevê um direito individual protetivo, seja em relação ao próprio Estado, seja em relação aos demais indivíduos” (MORAES, 2011, p. 48) e “(...) estabelece um dever fundamental de tratamento igualitário dos próprios semelhantes" (MORAES, 2011, p. 48).

Tais excertos representam a tendência constitucionalista moderna no sentido de se defender que a eficácia protetiva da dignidade da pessoa humana (assim como a dos demais direitos fundamentais) deve se dar não somente numa ótica vertical, mas também em âmbito horizontalizado, isto é, nas relações interpessoais.

Logo, o legislador, ao atribuir tamanha relevância ao princípio da dignidade da pessoa humana, demonstrou a necessidade de sua tutela como um valor espiritual e moral inerente à pessoa humana. (MORAES, 2011, p. 48)

Destaca-se, ainda, que todo e qualquer sujeito dispõe de uma série de atributos subjetivos que corroboram na formação de sua identidade e individualidade.

Desse modo, respeitar a dignidade humana implica em "respeitar a autodeterminação consciente responsável pela própria vida" (MORAES, 2011, p. 48), o que também a inclui como um direito de personalidade.

A garantia do tratamento isonômico entre todos os seres humanos e a vedação ao 
tratamento discriminatório e arbitrário, para Ingo Wolfgang Sarlet, são consideradas pressupostos para o respeito à dignidade da pessoa humana (SARLET, 2006, p. 122).

Deste modo, o princípio da dignidade da pessoa humana pode ser invocado para opor limites à liberdade de expressão, garantindo-se, desta forma, que a livre manifestação do pensamento corrobore com a emancipação da pessoa humana.

Nesse contexto, quando a liberdade de expressão é utilizada para manifestar pensamentos discriminatórios e intolerantes que desqualificam, inferiorizam e desumanizam uma pessoa ou determinado grupo em decorrência de características específicas, como as minorias sexuais, o princípio da dignidade da pessoa humana é extirpado, destacando-se que a dignidade violada é deste grupo como um todo.

Dessa forma, torna-se clara a colisão entre o direito fundamental da liberdade de expressão e o princípio da dignidade da pessoa humana.

A expressão do pensamento por meio da fala não se limita ao mero significado das palavras, mas explicita a existência de relações de poder que criam e definem a realidade social.(MELLO, 2015)

Desse modo, as práticas discursivas, enquanto linguagem em ação, são capazes de estabelecer a realidade e o significado social dos sentidos, acarretando, de fato, em consequências nefastas ao foro íntimo daquele que foi vítima do discurso do ódio. (LEITE, 2011)

O discurso, que suscita a desqualificação dos sujeitos pertencentes às minorias sexuais, explicita, também, a existência de relações de poder que ao longo da história atribuíram a posição de centralidade a determinados sujeitos a partir da exclusão daqueles que transpuseram a categorização binária proposta pela biologização das identidades sociais.

Considera-se que as manifestações discursivas que ultrapassam a liberdade de expressão e que atentam contra a dignidade das minorias sexuais disseminam a intolerância e incitam a violência contra esse grupo.

Nesse sentido, pode-se conceituar o discurso do ódio como a prática discursiva que tem como escopo discriminar um único indivíduo ou um determinado grupo de pessoas em razão de atributos que compõem sua identidade. 
Tal discurso implica, na visão de Samanta Ribeiro Meyer-Pflug, no conflito entre direitos fundamentais "que constituem a própria estrutura das sociedades democráticas, pois testa a abrangência e a extensão da proteção conferida à liberdade de expressão, à dignidade da pessoa humana, aos direitos das minorias".(MORAES, 2011, p. 23)

O discurso do ódio é uma manifestação "segregacionista, baseada na dicotomia superior (emissor) e inferior (atingido)",(SILVA, 2011) constituído por dois elementos, quais sejam: a discriminação e a exterioridade.(SILVA, 2011)

Deste modo, explicita-se, não somente a aversão ao grupo estigmatizado, mas também a constância de relações de poder hierarquicamente constituídas, das quais tais grupos sempre ficam às margens.

Diferentemente da liberdade de expressão, o discurso do ódio objetiva, na verdade, impor condutas anti-igualitárias e cercear a diversidade, disseminando a intolerância e o ódio, violando-se, assim, a dignidade humana, podendo gerar um conflito entre esta e a liberdade de expressão.

Portanto, deve-se apurar até onde se opera a liberdade de expressão e a partir de que momento se inicia uma prática discursiva odiosa, discriminatória.

Caso se verifique que a conduta se encontra dentro dos limites da liberdade, deve-se confrontá-la com a dignidade para que, tecnicamente e mediante os ideários de justiça de um Estado Democrático de Direito, seja possível se concluir qual das duas deve prevalecer ao se analisar cada situação específica.

\section{DO PRINCÍPIO DA PROPORCIONALIDADE}

Tendo em vista que as normas de direitos fundamentais, em sua estrutura,constituem princípios, devem ser compreendidas como mandamentos de otimização. (ALEXY, 2014, p. 90)

Acerca do tema, Robert Alexy afirma:

(...) os princípios são normas que ordenam que algo seja realizado na maior medida possível dentro das possibilidades jurídicas e fáticas existentes. Princípios são, por conseguinte, mandamentos de otimização, que são 
caracterizados por poderem ser satisfeitos em graus variados e pelo fato de que a medida devida de sua satisfação não depende somente das possibilidades fáticas, mas também das possibilidades jurídicas. (ALEXY, 2014, p. 90)

J.J. Gomes Canotilho complementa, afirmando que a reserva do possível, fática ou jurídica, deve ser observada na otimização do direito ou do bem jurídico.(CANOTILHO, 2002, p. 1241)

Justamente devido à natureza principiológica dos direitos fundamentais é que, em face de colisão entre esses direitos, deve-se observar qual deles possui maior peso no caso concreto (ALEXY, 2014, p. 90), já que, como se disse, sequer tal categoria de direitos tem caráter absoluto.

Acerca da possibilidade de restrição aos direitos fundamentais, Daniel Sarmento disserta:

Já se tornou lugar-comum a afirmação de que, apesar da relevância ímpar do papel que desempenham nas ordens jurídicas democráticas, os direitos fundamentais não são absolutos. A necessidade de proteção de outros bens jurídicos diversos, também revestidos de envergadura constitucional, pode justificar restrições aos direitos fundamentais. (...) a doutrina e a jurisprudência dominantes, no Brasil e no Direito Comparado, admitem também a realização de restrições a direitos fundamentais operados no caso concreto, através de ponderações de interesses feitas diretamente pelo Poder Judiciário. (SARMENTO, 2006, p. 295)

$\mathrm{Na}$ presente análise, a problematização ocorre quando o direito fundamental à liberdade de expressão é utilizado com o intuito de discriminar determinado grupo de pessoas em função de atributos específicos.

O discurso do ódio, sob o argumento da liberdade de expressão, acaba sendo habitualmente proferido com o escopo de neutralizar as demandas de grupos minoritários e vulneráveis.

Assim, ocorre explícita colisão do referido direito fundamental extraído da liberdade com a dignidade da pessoa humana.

Acerca das limitações da liberdade de expressão decorrentes de conflitos com outros 
direitos fundamentais, Valéria Silva Galdino Cardin e Tatiane Giovanini de Freitas Mochi ressaltam que:

\begin{abstract}
(...) a liberdade de expressão possui um efeito irradiante sobre a ordem jurídica, porque vincula não só o Estado como também os particulares. Trata-se da eficácia horizontal dos direitos fundamentais. Em caso de colisão entre tais direitos, o princípio da proporcionalidade é um importante aliado, porque permite racionalizar soluções a partir de critérios pré-estabelecidos. Assim, deve ser analisado se a medida ou o meio que restringe um direito é adequado e necessário para a consecução do fim pretendido, que é a satisfação de outro direito. Além disso, impende realizar uma ponderação em sentido estrito, a fim de que haja o menor sacrifício possível dos bens jurídicos tutelados em conflito. (CARDIN; MOCCHI, 2012)
\end{abstract}

A partir do momento em que se buscar legitimar o discurso do ódio com base na liberdade de expressão, estabelece-se um conflito entre direitos fundamentais, isso é, interesses constitucionalmente garantidos. (MEYER-PFLUG, 2009, p. 255)

Dessa forma, é necessário utilizar-se do princípio da proporcionalidade para que haja a solução da colisão no caso concreto.

Acerca da relatividade dos direitos fundamentais, Alexandre de Moraes preceitua que:

Os direitos e garantias fundamentais consagrados pela Constituição Federal, portanto, não são ilimitados (...). Dessa forma, quando houver conflito entre dois ou mais direitos ou garantias fundamentais, o intérprete deve utilizar-se do princípio da concordância prática ou da harmonização, de forma a coordenar e combinar os bens jurídicos em conflito, evitando o sacrifício total de alcance de cada qual (contradição dos princípios), sempre em busca do verdadeiro significado da norma e da harmonia do texto constitucional com suas finalidades.(grifos do autor) (MORAES, 2011, p. 27)

Assim, por meio do princípio da proporcionalidade, há de se estabelecer uma ponderação entre os valores tutelados pelos direitos fundamentais em conflito. Para se analisar essa técnica interpretativa, deve-se traçar seu panorama histórico.

O conceito do princípio da proporcionalidade começou a ser construído a partir das ideias iluministas e liberais, que tiveram importante papel na consolidação dos direitos do homem e/ou fundamentais, em contraposição àquelas vigentes até então no Estado absolutista. (SARMENTO, 2004, p. 21)

De qualquer modo, ressalte-se que, no ano de 350 anos a.C., Aristóteles já falava na importância do justo meio. (FACHIN, 2001, p. 55)

No século XVIII, então, emergiu a discussão sobre a proporcionalidade no sentido de 
se limitar o poder estatal. Nas palavras de Raquel Denize Stumm:"medida com valor suprapositivo ao Estado de Direito que visa garantir a esfera de liberdade individual das ingerências administrativas" (STUMM, 1995, p. 78). Em outras palavras, à época buscava-se a tutela do princípio da proporcionalidade (e dos demais direitos fundamentais, é claro), apenas no que tange à sua eficácia vertical, já que o Estado absolutista correspondia ao maior violador de direitos fundamentais.

Tal princípio, no referido momento histórico, relacionava-se apenas com as áreas administrativa e penal, tanto é que Montesquieu e Beccaria trataram da proporcionalidade das penas em relação aos delitos. (STUMM, 1995, p. 78).

Em continuidade ao interesse em se acabar com a mencionada arbitrariedade estatal, o século XIX fica, então, marcado pela necessidade da formalização da aplicação de tal princípio (STUMM, 1995, p. 78), havia uma vontade geral de constituição. Constituição essa emancipadora, garantista das liberdades individuais.

Entretanto, somente em meados do século seguinte, na Alemanha severamente abalada com o cenário trágico deixado pela Segunda Guerra Mundial, que se valeu de condutas desumanas, a proporcionalidade adquiriu foro constitucional e passou a ser reconhecida como princípio, o que ganhou repercussão internacional e, paulatinamente, passou a permear os diversos ordenamentos jurídicos.

No Brasil, somente com o advento da Constituição Federal de 1988 é que o interesse de doutrinadores e estudiosos sobre o princípio da proporcionalidade foi despertado, passando o tema a ser tardiamente discutido, isto é, a partir da década de 1990. (FACHIN, 2013, p. 140).

A Constituição Cidadã consagrou o modelo de Estado do Bem-Estar Social (Welfare State) (SARMENTO, 2004, p. 33) em consonância com seu momento histórico pós-ditatorial e a tendência mundial, e definiu o extenso rol de garantias e direitos fundamentais (SARMENTO, 2004, p. 108), bem como uma série de princípios de axiologia derivada dos ideais revolucionários da igualdade, liberdade e fraternidade (SARMENTO, 2004, p. 24). Todavia, não tratou da proporcionalidade de forma expressa em seu texto, o que foi motivo de 
grandes controvérsias técnicas.

Após longas discussões a respeito de a proporcionalidade ter sido admitida ou não pelo ordenamento jurídico brasileiro vigente, chegou-se à conclusão que, de fato, trata-se de princípio implícito ao sistema constitucional.

Isso porque, conforme o entendimento, deriva do Princípio do Estado de Direito, da cláusula do devido processo legal, da disposição do parágrafo $2^{\circ}$. do artigo $5^{\circ}$. da Constituição Federal de 1988 ou do conteúdo dos direitos fundamentais, sendo este último o argumento que se defende no presente estudo.

Nesse diapasão, diante do confronto de dois princípios constitucionais que envolvam direitos fundamentais, sem que seja possível proteger a ambos, deve prevalecer o direito fundamental de maior relevância no caso concreto, de modo que um seja mitigado e o outro preservado, justamente porque nenhum deles é absoluto, como se sustenta.

Por essa razão, trata-se de instrumento de interpretação da constituição (FACHIN, 2013, p. 140). Destaque-se que se está diante de uma relação de precedência ou prevalência, em vez de relação de subsunção, porque, ao contrário das regras (às quais se aplica o critério do tudo ou nada), os princípios são razões apenas prima facie (ALEXY, 2015, p. 106), isto é, aplicáveis num primeiro momento, admitindo posteriores restrições ou interpretações variadas.

Continuando o raciocínio, Alexy ressalta que as antinomias existentes entre regras jurídicas se resolvem pela inserção de uma cláusula de exceção ou no âmbito da validade (ALEXY, 2015, p. 106), pela aplicação dos critérios clássicos (hierárquico, cronológico e de especialidade). Segundo Daniel Sarmento, os critérios aplicáveis às regras correspondem a um "raciocínio calcado na lógica formal, alheio às preocupações morais substantivas" (SARMENTO, 2004, p. 94).

Já os conflitos entre princípios, ao contrário, se resolvem pela dimensão de peso e estão mais próximos à ideia de direito.

Raquel Stumm trata da proporcionalidade em sentido amplo como sinônimo do princípio da proibição de excesso (STUMM, 1995, p. 78), que se vale do método da ponderação de resultados (STUMM, 1995, p. 77) para se avaliar, no caso concreto, a colisão entre direitos ou entre direitos e valores (veiculados por princípios e normas), desde que se refiram a bens constitucionalmente protegidos. (STUMM, 1995, p. 76) 
Marco Aurélio Mello aponta o princípio da proporcionalidade como um mecanismo eficaz para realizar a ponderação exigida no caso concreto. (MELLO, 2009, p. 246)

Para o autor:

O conteúdo central do princípio da proporcionalidade é formado por subprincípios que abarcam parcialmente certa amplitude semântica da proporcionalidade. São eles a idéia de conformidade ou de adequação dos meios, a exigibilidade ou necessidade desses meios e a proporcionalidade em sentido estrito. (MELLO, 2009, p. 246)

Em outras palavras, para que se aplique o princípio da proporcionalidade, há de se observar, se a solução encontrada é razoável para o fim desejado, se constitui o meio mais eficaz para resolver o conflito e se, de fato, é indispensável.

Assim, a proporcionalidade pode ser dividida em três elementos, que consistem nas máximas parciais da adequação, necessidade e proporcionalidade em sentido estrito, justamente de acordo com a fundamentação da referida máxima a partir dos direitos fundamentais, em que Alexy leciona que a adequação e a necessidade correspondem ao elemento fático da proporcionalidade, enquanto que a proporcionalidade em sentido estrito constitui seu elemento jurídico. (ALEXY, 20015, p. 120)

De modo mais detalhado, observa-se que a adequação representa uma relação empírica entre meio e fim (ÁVILA, 2005, p. 118), relacionados à restrição e à promoção do que se deseja. Nessa perspectiva, para que um ato seja considerado proporcional, o meio utilizado deve ser idôneo, apto a atingir ou promover o fim almejado.

A necessidade, por sua vez, também chamada de exigibilidade ou de princípio da menor ingerência possível, implica em, após se admitir a existência de diversos meios hábeis para o atendimento de um determinado fim, optar-se pelo menos gravoso dentre eles. (ÁVILA, 2005, p. 118) Buscando-se, por meio dela, atingiras liberdades individuais ao mínimo. 
Quanto à proporcionalidade em sentido estrito, analisa-se a relação entre o custo da medida adotada e os benefícios trazidos por ela.

A referida máxima parcial concerne no sopesamento entre a intensidade da restrição ao direito fundamental atingido e a importância da realização do direito fundamental a ser promovido.

Nessa perspectiva, a proporcionalidade, como instrumento de interpretação da constituição, pode ser concebida no Brasil como princípio constitucional implícito ou máxima aplicável ao caso concreto que busca eliminar o conflito de princípios constitucionais veiculadores de direitos fundamentais, mediante cedência recíproca no sopesamento entre eles, já que se deve estabelecer os limites e a atuação de cada um diante das realidades fáticas que se apresentarem.

Tal princípio deriva do conteúdo dos direitos fundamentais e, por isso, corresponde a importante meio de proteção do cidadão frente ao Estado. Mas a fundamentação a partir dos direitos fundamentais não se encerra aí.

Atualmente, percebe-se também como uma garantia do cidadão de que seu próximo respeite sua esfera pessoal, de modo que nenhum particular possa comprometer os direitos fundamentais do outro, o que constitui a já mencionada eficácia horizontal dos direitos fundamentais.

Como as práticas sociais são estabelecidas por sua própria historicidade, a prevalência de um direito fundamental em relação ao outro também o é.

Desta forma, não se pode defender previamente a superioridade de um em detrimento do outro, mas deve-se analisar o conflito caso a caso para, tecnicamente, ser possível afirmar qual dos valores em questão deverá predominar. No caso, a liberdade de expressão ou a dignidade da pessoa humana.

Em outras palavras, mesmo a dignidade da pessoa humana fundamentando a liberdade de expressão e o discurso do ódio parecendo ser um abuso da liberdade mencionada, a prevalência somente pode se apurar mediante o estudo do caso concreto.

\section{CONCLUSÃO}


Muito embora a liberdade de expressão seja considerada como um direito fundamental, não pode ser compreendia como um direito absoluto.

Observa-se que quando a liberdade à manifestação do pensamento colidir com outros direitos fundamentais ou bens constitucionalmente tutelados, deve prevalecer aquele que, no caso concreto, represente de maneira mais eficaz a efetivação da proteção do sujeito de forma ampla.

Para tanto, como meio de solução do conflito entre direitos fundamentais e princípios constitucionais, sugere-se a aplicação do princípio da proporcionalidade, em que, a partir da análise das especificidades do caso, pode ser estabelecido qual direito fundamental melhor representa a proteção do sujeito de forma integral, isto é, qual bem jurídico merece amparo prioritário.

Hodiernamente, observa-se, que a liberdade de expressão pode ser utilizada para manifestar pensamentos discriminatórios com o intuito de diminuir, insultar e desqualificar determinadas pessoas e grupos em virtude de características pessoais, legitimando, assim, o discurso do ódio.

Deste modo, explicitam-se, por meio do discurso do ódio, a prevalência não somente da aversão ao grupo estigmatizado, mas também a constância de relações de poder hierarquicamente constituídas.

Diferentemente da liberdade de expressão, o discurso do ódio objetiva, na realidade, impor condutas anti-igualitárias e cercear a diversidade, disseminando a intolerância e o ódio, violando-se, assim, a dignidade humana, podendo gerar um conflito entre esta dignidade e a liberdade de expressão.

Portanto, deve-se apurar até onde se opera a liberdade de expressão e a partir de que momento se inicia uma prática discursiva odiosa e discriminatória, capaz não apenas de demonstrar o pensamento odioso, mas de gerar efeitos concretos nos grupos sociais estigmatizados.

Caso, então, venha se verificar que a conduta se encontra dentro dos limites da liberdade, deve-se confrontá-la com a dignidade para que, tecnicamente e mediante os ideários de justiça do Estado Democrático de Direito, seja possível se concluir qual das duas 
deve prevalecer.

O discurso do ódio, quando proferido contra as minorias sexuais - estimulando-se, ainda que veladamente, a prática de ações discriminatórias e preconceituosas - viola não somente a dignidade do indivíduo vítima da ofensa, mas a dignidade deste grupo social como um todo.

Mais do que simples liberdade de expressão, o discurso do ódio objetiva, exclusivamente, impor condutas anti-igualitárias e cercear a diversidade, disseminando a intolerância e o ódio, violando-se, assim, a dignidade humana e, consequentemente, gerando um conflito entre esta a liberdade de expressão.

Observando-se presentes os conflitos entre o exercício da liberdade de expressão e a dignidade da pessoa humana, utilizando-se da aplicação do princípio da razoabilidade, há de se observar o caso concreto.

Desde modo, é certo que, analisando-se o caso concreto, a liberdade de expressão será mitigada quando for utilizada visando a legitimar o discurso do ódio, ensejando riscos concretos à dignidade das minorias sexuais. Todavia, repita-se, issto não dispensa a análise pontual da situação 


\section{BIBLIOGRAFIA}

ALEXY, Robert. Teoria dos direitos fundamentais. Trad. Virgílio Afonso da Silva. 2. ed. São Paulo: Malheiros Editores, 2014.

ARISTÓTELES. Ética a Nicômaco. Trad. Pietro Nassetti. São Paulo: Martin Claret, 2001.

ÁVILA, Humberto. Teoria dos Princípios: da definição à aplicação dos princípios jurídicos. 4. ed. São Paulo: Malheiros, 2005.

BONAVIDES, Paulo. Do Estado Liberal ao Estado Social. 6. ed. São Paulo: Malheiros, 1996.

CANOTILHO, J.J. Gomes. Direito constitucional e teoria da Constituição. 6.ed. Coimbra: Almedina, 2002.

CARDIN, Valéria Silva Galdino;MOCHI, Tatiana de Freitas Giovanini. Dos limites da liberdade de expressão nos meios de comunicação em massa diante dos direitos fundamentais da criança e do adolescente. In: CONPEDI. (Org.). Encontro Nacional do CONPEDI (21. : 2012: Uberlândia, MG). Florianópolis: Fundação Boiteux, 2012.

FACHIN, ZULMAR. Curso de Direito Constitucional. 6. ed. Rio de Janeiro: Forense, 2013.

LEITE, Miriam S. Significação da violência e heteronormatividade no contexto da prática curricular. Revista e-Curriculum, vol. 7, núm. 1, abril, 2011, pp. 1-18, Pontifícia Universidade Católica de São Paulo Disponível em:

<http://www.redalyc.org/articulo.oa?id=76619165014.> . Acesso em: 20 jun. 2015.

MELLO, Marco Aurélio. Liberdade de expressão, dignidade humana e estado democrático de 
direito. In: MIRANDA, Jorge; SILVA, Marco Antônio Marques da (coords.) Tratado LusoBrasileiro da Dignidade Humana. São Paulo: QuartierLatin, 2009.

MELLO, Ricardo Pimentel et al .Construcionismo, práticas discursivas e possibilidades de pesquisa em psicologia social. Psicol. Soc., Porto Alegre, v. 19, n. 3, Dec. 2007.

Disponível em: <http://www.scielo.br/scielo.php?script=sci_arttext\&pid=S0102$71822007000300005 \& \operatorname{lng}=\mathrm{en} \& n r m=\mathrm{iso}>$. Acesso em 20 jun. 2015.

MEYER-PFLUG, Samantha Ribeiro. Liberdade de expressão e discurso do ódio. São Paulo: Revista dos Tribunais, 2009.

MORAES, Alexandre de. Direitos humanos fundamentais: teoria geral, comentários aos arts. $1^{\circ}$ a $5^{\circ}$ da Constituição da República Federativa do Brasil, doutrina e jurisprudência. $9^{a}$ ed. São Paulo: Atlas, 2011.

SARLET, Ingo Wolfgang. A eficácia dos direitos fundamentais. $6^{\mathrm{a}}$. ed. Porto Alegre: Livraria do Advogado, 2006.

SARLET, Ingo Wolfgang. Dignidade da pessoa humana e direitos fundamentais na Constituição Federal de 1988. Porto Alegre: Livraria do Advogado, 2001.

SARMENTO, Daniel. Colisões entre direitos fundamentais e interesses públicos. In: SARMENTO, Daniel; GALDINO, Flávio (org.) Direitos fundamentais: estudos em homenagem ao professor Ricardo Lobo Torres. Rio de Janeiro: Renovar, 2006.

SARMENTO, Daniel. Direitos Fundamentais e Relações Privadas. Rio de Janeiro: Lumen Juris, 2004.

SILVA, Marco Antônio da. Cidadania e democracia: instrumentos para a efetivação da dignidade humana. In: MIRANDA, Jorge; SILVA, Marco Antônio Marques da (coords.) Tratado Luso-Brasileiro da Dignidade Humana. São Paulo: QuartierLatin, 2009.

SILVA, Rosane Leal da et al . Discursos de ódio em redes sociais: jurisprudência brasileira. RevistaDireitoGV, São Paulo, v. 7, n. 2, dez. 2011. Disponível em: $<$ http://www.scielo.br/scielo.php?script=sci_arttext\&pid=S1808-

$24322011000200004 \& \operatorname{lng}=$ en\&nrm=iso>. Acesso em 20 jun. 2015. 
SIQUEIRA JR, Paulo Hamilton. A dignidade da pessoa humana no contexto da pósmodernidade. In: MIRANDA, Jorge; SILVA, Marco Antônio Marques da (coords.) Tratado Luso-Brasileiro da Dignidade Humana. São Paulo: QuartierLatin, 2009. p. 273.

STUMM, Raquel Denize. Princípio da Proporcionalidade no Direito Constitucional Brasileiro. Porto Alegre: Livraria do Advogado, 1995. 